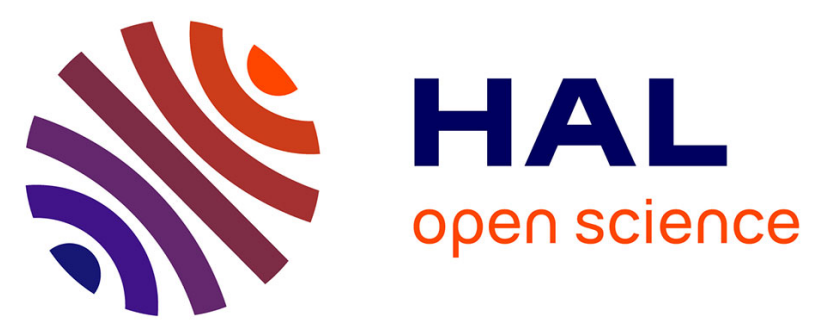

\title{
The spectrum of neuropsychiatric symptoms in patients with early, untreated Parkinson's disease.
}

\author{
Dag Aarsland, Kolbjørn Brønnick, Guido Alves, Ole-Bjørn Tysnes, Kenn
}

Freddy Pedersen, Uwe Ehrt, Jan Petter Larsen

\section{- To cite this version:}

Dag Aarsland, Kolbjørn Brønnick, Guido Alves, Ole-Bjørn Tysnes, Kenn Freddy Pedersen, et al.. The spectrum of neuropsychiatric symptoms in patients with early, untreated Parkinson's disease.. Journal of Neurology, Neurosurgery and Psychiatry, 2009, 80 (8), pp.928. 10.1136/jnnp.2008.166959 . hal00552740

\section{HAL Id: hal-00552740 \\ https://hal.science/hal-00552740}

Submitted on 6 Jan 2011

HAL is a multi-disciplinary open access archive for the deposit and dissemination of scientific research documents, whether they are published or not. The documents may come from teaching and research institutions in France or abroad, or from public or private research centers.
L'archive ouverte pluridisciplinaire HAL, est destinée au dépôt et à la diffusion de documents scientifiques de niveau recherche, publiés ou non, émanant des établissements d'enseignement et de recherche français ou étrangers, des laboratoires publics ou privés. 
The spectrum of neuropsychiatric symptoms in patients with early, untreated Parkinson's disease.

\author{
D. Aarsland ${ }^{1,2,3}$, K. Brønnick ${ }^{1}$, G. Alves ${ }^{1,4}$, O.B. Tysnes ${ }^{3,5}$, \\ K.F. Pedersen ${ }^{1,4}$, U. Ehrt ${ }^{1,2}$, J.P. Larsen ${ }^{1,3,4}$
}

${ }^{1}$ The Norwegian Centre for Movement Disorders, Stavanger University Hospital, Stavanger, Norway ${ }^{2}$ Department of Psychiatry, Stavanger University Hospital, Stavanger, Norway ${ }^{3}$ School of Medicine, University of Bergen, Bergen, Norway

${ }^{4}$ Department of Neurology, Stavanger University Hospital, Stavanger, Norway

${ }^{5}$ Department of Neurology, Haukeland University Hospital, Bergen, Norway

Corresponding author

Dag Aarsland

Stavanger University Hospital

The Norwegian Centre for Movement Disorders

PO Box 8100

4068 Stavanger

Norway

E-mail: daarsland@gmail.com, telephone: +4797575804, fax: +4751515515

$\underline{\text { Key words }}$

Parkinson's disease, neuropsychiatric symptoms, apathy, depression, cluster analysis

\title{
$\underline{\text { Word count }}$
}

1705 words 


\section{ABSTRACT}

Background: Neuropsychiatric symptoms are common in Parkinson's disease (PD), and have important clinical consequences for patients, caregivers and society. Few studies of neuropsychiatric symptoms in early, untreated PD exist.

Objective: To explore the range, clustering and correlates of neuropsychiatric symptoms in an incidence-cohort of untreated subjects with PD.

Methods: All cases with incident PD identified during a 22-months period in four counties of Western and Southern Norway were included. Standardized criteria were employed to diagnose PD. The Neuropsychiatric Inventory (NPI) was administered to 175 PD and 166 healthy control subjects with similar age and sex distribution. Cluster analysis was used to investigate the inter-relationship of NPI items.

Results: The proportion with any symptom and severity of NPI symptoms was higher in PD $(56 \%)$ than in controls $(22 \%)(\mathrm{p}<.001)$. Depression $(37 \%)$, apathy $(17 \%)$, sleep disturbance (20\%) and anxiety (17\%) were the most common symptoms. Clinical significant symptoms occurred in $27 \%$ of the PD group, compared to only $3 \%$ in the control group ( $p<.001)$. Subjects with clinically significant neuropsychiatric symptoms had more severe parkinsonism than those without. Two neuropsychiatric clusters were identified, one characterised by mood symptoms and one by apathy. Conclusions: Although the majority of patients with early, untreated PD do not have clinical significant neuropsychiatric symptoms, these symptoms are more common in patients than in people without PD. Both psychological stress and brain changes associated with PD are likely to contribute to the higher frequencies. 


\section{INTRODUCTION}

A wide range of neuropsychiatric symptoms have been described in PD, with important clinical consequences both for patients, caregivers and society.[1] However, no population-based studies of the spectrum of neuropsychiatric symptoms exist in patients with early unmedicated PD. Since antiparkinsonian drugs have the potential to influence a range of psychiatric symptoms, including affective symptoms, cognition, impulsivity, and psychotic symptoms,[2] studying drug-naïve patients is required to explore behavioural changes that are related to the disease itself.

Therefore, we administered the Neuropsychiatric Inventory (NPI)[3] to a large, unselected sample of patients with incident, non-demented, untreated PD and matched controls, derived from the Norwegian ParkWest project, a multicentre populationbased longitudinal cohort study.

\section{METHODS}

\section{Patients and controls}

Case ascertainment, patient selection and diagnosis are described in an accompanying paper. From 206 subjects who were spouses or friends of the patients, or unrelated persons from the study area, the 175 subjects who provided the best possible match regarding age- and sex-distribution and years of education to the eligible patients with PD were included as a control group.

\section{Neuropsychiatric assessment}

The NPI was used to assess frequency and intensity of 12 neuropsychiatric symptoms. The maximum possible score is 12 , and a score of $\geq 4$ is usually considered to represent clinical significant severity. In two subjects with missing data on one or two 
items, a score of 0 was recorded on the missing item, whereas subjects with missing data on more than two items were excluded. Motor symptoms were rated using the Unified Parkinson's Disease Rating scale (UPDRS) subscale III.[4]

Neuropsychological assessment included the Mini-Mental State Examination (MMSE) [5], a battery of neuropsychological tests and standardised history of cognitive impairment, and subjects with probable dementia associated with PD at examination were excluded. See [6] for a detailed description of procedures and criteria to diagnose dementia.

\section{Statistics}

Due to non-linearity of NPI subscores, non-parametric analyses (Spearman correlation and Mann-Whitney test) were used to estimate associations between NPI and demographic and clinical features. To explore how the different psychiatric symptoms clustered in individual patients, we performed cluster analyses. The NPI subscores of each patient were standardized to $z$-score values based on the mean and standard deviation of each NPI variable. This was performed in order to ensure equal weighting of the different symptoms in the clustering procedure. A similarity matrix was calculated using a Euclidean distance measure.[3] A Ward-method clusteranalysis was used on the similarity matrix. For validation purposes we also employed an average-linkage cluster analysis. The material was considered too small to perform a split-sample validation procedure. To identify the appropriate number of clusters, we plotted the overall within-group sum of squares over all the included variables and investigated the plot for an "elbow". P-values below 0.05 were considered statistically significant. 


\section{RESULTS}

Among the 201 eligible PD patients and 175 normal controls, 19 PD and 9 control subjects were not administered the NPI or had missing data on more than two items. Further seven patients were excluded due to dementia, leaving 175 PD patients and 166 healthy control subjects for inclusion. The patients had lower mean MMSE score (27.8, SD 2.3) than the control subjects (28.6, SD 1.5) $(\mathrm{p}=0.001)$, and slightly less years of formal education (10.9 (2.3) vs $11.6(3.5), \mathrm{p}=0.04)$, but did not differ significantly regarding age (67.8 (9.0) vs $67.3(9.1), \mathrm{ns})$ and sex distribution (58\% vs $60 \%$ male, ns).

Table 1. Composite scores and proportions with positive and clinically significant item scores on the Neuropsychiatric Inventory in early PD and control subjects

\begin{tabular}{|l|c|c|c|c|c|c|}
\hline \multirow{2}{*}{} & \multicolumn{2}{|c|}{ Mean score } & \multicolumn{2}{c|}{$\begin{array}{c}\text { \% with a } \\
\text { positive score }\end{array}$} & $\begin{array}{c}\text { \% with a clinically } \\
\text { significant score* }\end{array}$ \\
\cline { 2 - 7 } & NC & PD & NC & PD & NC & PD \\
\hline Delusions & 0.0 & 0.06 & 0 & 1.1 & 0 & 0.6 \\
\hline Hallucinations & 0.01 & 0.04 & 0.6 & 1.2 & 0 & 0.6 \\
\hline Agitation & 0.02 & 0.15 & 1.2 & 5.7 & 0 & 1.1 \\
\hline Depression & 0.11 & 1.06 & 7.8 & 34.3 & 0.6 & 10.3 \\
\hline Anxiety & 0.07 & 0.59 & 2.4 & 16.4 & 0.6 & 6.9 \\
\hline Euphoria & 0 & 0 & 0 & 0 & 0 & 0 \\
\hline Apathy & 0.03 & 1.06 & 1.2 & 27.4 & 0 & 11.4 \\
\hline Disinhibition & 0 & 0.08 & 0 & 4.0 & 0 & 0.6 \\
\hline Irritability & 0.14 & 0.22 & 5.4 & 8.6 & 1.2 & 1.7 \\
\hline Motor behaviour & 0.02 & 0.14 & 0.6 & 2.3 & 0.6 & 1.7 \\
\hline Sleep disturbance & 0.2 & 0.69 & 9.1 & 17.8 & 1.8 & 7.5 \\
\hline Appetite disturbance & 0.09 & 0.70 & 1.8 & 14.9 & 0.6 & 8.0 \\
\hline
\end{tabular}

${ }^{*}$ clinically significant neuropsychiatric symptoms defined as a NPI score of $\geq 4$ $P D=$ Parkinson's disease $;$ N $=$ normal controls 
The NPI item scores and proportion with symptoms are shown in table 1 . The total NPI score, number of symptoms and number of symptoms with a clinically significant severity differed significantly between the groups (Mann-Whitney test, all p values $<0.001)$. Ninety-eight $(56 \%)$ of the PD group had a positive score on at least one item, compared to $36(21.7 \%)$ in the control group (chi square $=42.0, \mathrm{p}<0.001)$. In the PD group, depression (34.3\%), apathy (27.4\%), sleep disturbance (17.8\%) and anxiety $(16.4 \%)$ were the most common symptoms. The number of positive NPI items was higher in PD patients than control subjects $(Z=-7.2, p<.001)$, with $61(34.9 \%)$ patients having more than one symptom compared to only 10 (6.0\%) in the control group.

Forty-seven (26.9\%) PD patients had at least one symptom of clinically significance, the most common being apathy $(11.4 \%)$, depression (10.3\%), appetite (8\%), and sleep (7.5\%) disturbances, compared to only $5(3.0 \%)$ in the control group having a symptom of clinically significant severity $(\mathrm{p}<0.001)$. PD patients had more symptoms of clinically significant severity than control subjects $(Z=-6.1, p<0.001)$, and 22 (12.6\%) PD patients had more than one clinically significant symptom, compared to only $2(1.2 \%)$ in the control group.

Patients with at least one clinically significant score had higher UPDRS motor subscale score $(29.5(13.7))$ than those without clinically significant neuropsychiatric symptoms $(21.5(9.7), \mathrm{t}=4.3, \mathrm{p}<0.001)$, whereas the MMSE score or sex distribution did not differ significantly.

Antidepressant drugs were used by 23 (13.1\%), one (0.6\%) used an antipsychotic, and a benzodiazepine was used by 21 (12\%) (regularly by 19 , intermittently by 2 ). The proportions taking antidepressants $(35.6 \%$ vs $5.8 \%$; chi square $26.1, \mathrm{p}<0.001)$ and 
benzodiazepine $(26.7 \%$ vs $5.5 \%$; chi square 15.3 , p<0.001) were higher among those with at least one significant neuropsychiatric symptom compared to those without significant neuropsychiatric symptoms.

Cluster-analysis was performed to explore whether groups with specific neuropsychiatric syndromes could be identified. Five clusters were identified, based on the finding of a very clear "elbow", indicating that there was little added benefit of increasing the cluster count from 5 to 6 . When dividing in two samples, 166 of 175 patients $(94.8 \%)$ were classified in the same clusters, supporting the validity of the cluster solution. Two of the clusters contained only 1 and 2 patients and were discarded, with three clusters remaining: The majority of patients $(n=158,90.3 \%)$ fell into a cluster with no or very mild symptoms (Cluster 1). Cluster 2 consisted of patients with mood symptoms ( $\mathrm{n}=10 ; 5.7 \%)$, ie high scores on the depression, anxiety, and apathy items, and a final small cluster $3(n=4,2.3 \%)$ consisted of patients with predominant high apathy score. The three clusters differed significantly in cognition and motor impairment, with the patients in the apathy cluster being more impaired than the other groups (table 2).

Table 2. Demographic and clinical features of early PD patients in the two neuropsychiatric clusters and in those with no or mild neuropsychiatric symptoms

\begin{tabular}{|l|c|c|c|c|c|}
\hline & $\begin{array}{c}\text { No/mild } \\
\text { symptoms }\end{array}$ & $\begin{array}{c}\text { Mood } \\
\text { cluster }\end{array}$ & $\begin{array}{c}\text { Apathy } \\
\text { cluster }\end{array}$ & Statistic & $\boldsymbol{p}$ \\
\hline Age & $67.5(9.0)$ & $69.0(9.1)$ & $75.1(8.7)$ & 1.5 & 0.24 \\
\hline Male/Female (n) & $90 / 58$ & $7 / 3$ & $3 / 1$ & 1.1 & 0.3 \\
\hline Education, years & $11.0(3.3)$ & $10.0(4.0)$ & $8.4(1.8)$ & 1.6 & 0.21 \\
\hline MMSE score & $27.9(2.4)$ & $28.0(2.1)$ & $24.5(1.7)$ & 4.0 & 0.02 \\
\hline UPDRS motor score & $22.8(11.2)$ & $31.7(9.7)$ & $35.3(11.5)$ & 5.1 & 0.007 \\
\hline
\end{tabular}

Numbers represent mean and $S D$ if not otherwise indicated.

UPDRS motor=Unified Parkinson's Disease Rating Scale, motor subscale MMSE=Mini-Mental State Examination Scale 


\section{DISCUSSION}

This study demonstrates for the first time that a characteristic neuropsychiatric symptom pattern can be found in early, drug-naïve patients with PD. More than half of the patients exhibited at least one symptom, and more than a quarter had at least one symptom of clinically significant severity. Several patients had two or more symptoms, and $13 \%$ had two or more clinically significant symptoms. Depression, anxiety, sleep disturbances and apathy were the most common symptoms, whereas psychotic symptoms were very rare.

The cluster analysis identified two neuropsychiatric syndromes, one with mood symptoms and one with predominantly apathy. This observation is consistent with previous studies. Studies of medium staged PD, ie Hoehn \& Yahr stage 3-4, have reported neuropsychiatric clusters, including depression, anxiety, and apathy clusters and a psychosis cluster.[7] In a cohort consisting of patients with advanced PD and dementia, a group with agitation and a variety of symptoms was added to mood, apathy, and psychosis groups.[8] Thus, the spectrum of neuropsychiatric symptoms tends to widen with more advanced disease. In early PD, mood and apathy are the predominating neuropsychiatric symptoms. Subsequently, with advancing disease, a group with hallucinations occurs, and in later stages with dementia, a group of patients exhibit multiple and severe neuropsychiatric symptoms including agitation.

The aetiology of neuropsychiatric symptoms in PD is most likely multifactorial, with possible contribution from both psychological stress and brain changes associated with PD. At this early disease stage, the motor symptoms are usually mild with little functional impairment, but the knowledge of having been diagnosed with a chronic, progressive and debilitating brain disease with potentially negative effect on their job 
situation, economic security and quality of life [9] may induce mood symptoms such as sadness and anxiety. On the other hand, both depression and anxiety can develop before the onset of motor symptoms and the diagnosis of $\mathrm{PD},[10]$ strongly suggesting that brain changes occurring early in disease may render the patients more likely to develop psychiatric symptoms.

Neuropsychiatric symptoms were associated with cognitive impairment. Care was taken to exclude any patient with dementia, and thus this finding adds to previous studies in demonstrating a relationship between psychiatric and cognitive disturbance even in early, non-demented patients. This provides further support for distinguishing PD patients with mild cognitive impairment from those with normal cognition, as a harbinger of dementia, as has been shown in imaging [11] and longitudinal [12] studies.

We found a relationship between motor severity and psychiatric symptoms in PD, consistent with previous studies.[7,13] The demonstration of such a relationship in drug-naïve patients is a novel finding, and suggests that to some degree, brain changes leading to motor symptoms and psychiatric morbidity develop in parallel, or have similar underlying brain substrates, ie dopaminergic, nigro-striatal disturbance.

The possibility of studying patients with early, drug-naive PD allows us to rule out the potential confounding effect of dopaminergic treatment on neuropsychiatric symptoms, which may affect a wide range of behavioural, motivational and emotional functions.[2] Antidepressants and anxiolytics were used by some patients, which might have influenced the findings by reducing the severity and frequency of depression and anxiety. Other limitations of the study include the cross-sectional 
design, precluding conclusions as to aetiology and course of neuropsychiatric symptoms.

In addition, important psychiatric symptoms such as obsessive-compulsive or impulse control disorders were not assessed. Although the NPI inquires about psychotic phenomena, it does not provide a systematic way of capturing the presence or character of the "minor "forms of psychosis in PD, such as illusions, passage and sense of presence hallucinations. Thus, such symptoms may have been present but not detected. Finally, the NPI assesses only severity of depression and anxiety, but provides no formal diagnosis, which would require a structured psychiatric interview.

Although the majority of patients with early untreated PD did not have clinical significant neuropsychiatric symptoms, this study shows that such symptoms are clearly more prevalent than in controls. We recommend that a screening of neuropsychiatric symptoms should be performed already at time of diagnosis of PD. Longitudinal studies are required to explore the predictive significance of neuropsychiatric symptoms, and how the profile of these symptoms evolve with time.

\section{COMPETING INTERESTS}

No competing interests.

\section{FUNDING}

This study was funded by the Western Norway Regional Health Authority (grant\# 911218) and the Research Council of Norway (grant\# 177966). 


\section{COPYRIGHT}

The Corresponding Author has the right to grant on behalf of all authors and does grant on behalf of all authors, an exclusive licence on a worldwide basis to the BMJ Publishing Group Ltd and its Licensees to permit this article (if accepted) to be published in the Journal of Neurology, Neurosurgery \& Psychiatry editions and any other BMJPGL products to exploit all subsidiary rights, as set out in our licence (http://jnnp.bmjjournals.com/ifora/licence.pdf)." 


\section{REFERENCES}

1. Choi J, Sullards MC, Olzmann JA, Rees HD, Weintraub ST, Bostwick DE, et al. Oxidative damage of DJ-1 is linked to sporadic Parkinson and Alzheimer diseases. J Biol Chem. 2006 Apr 21;281(16):10816-24.

2. Burn DJ, Troster AI. Neuropsychiatric complications of medical and surgical therapies for Parkinson's disease. Journal of geriatric psychiatry and neurology. 2004 Sep;17(3):172-80.

3. Cummings JL, Mega M, Gray K, Rosenberg-Thompson S, Carusi DA, Gornbein J. The Neuropsychiatric Inventory: comprehensive assessment of psychopathology in dementia. Neurology. 1994 Dec;44(12):2308-14.

4. Fahn S, Elton RL. Unified Parkinson's Disease Rating Scale. In: Fahn S, Marsden CD, Calne DM, Lieberman A, editors. Recent development in Parkinson's disease. Florham Park, NJ: MacMillan Health Care Information; 1987. p. 153-63.

5. Folstein M, Folstein SE, McHugh PR. "Mini-mental state". A practical method for grading the cognitive state of patients for the clinician. J Psychiatric Res. 1975;12:189-98.

6. Aarsland D, Bronnick K, Larsen JP, Tysnes OB, Alves G. Cognitive impairment in incident, untreated Parkinson disease: The Norwegian ParkWest Study. Neurology. 2008 Nov 19.

7. Kulisevsky J, Pagonabarraga J, Pascual-Sedano B, Garcia-Sanchez C, Gironell A. Prevalence and correlates of neuropsychiatric symptoms in Parkinson's disease without dementia. Mov Disord. 2008 Aug 16.

8. Aarsland D, Bronnick K, Ehrt U, De Deyn PP, Tekin S, Emre M, et al. Neuropsychiatric symptoms in patients with Parkinson's disease and dementia: 
frequency, profile and associated care giver stress. Journal of neurology, neurosurgery, and psychiatry. 2007 Jan;78(1):36-42.

9. Taylor AE, Saint-Cyr JA. Depression in Parkinson's disease: reconciling physiological and psychological perspectives. The Journal of neuropsychiatry and clinical neurosciences. 1990 Winter;2(1):92-8.

10. Ishihara L, Brayne C. A systematic review of depression and mental illness preceding Parkinson's disease. Acta neurologica Scandinavica. 2006 Apr;113(4):21120.

11. Beyer MK, Janvin CC, Larsen JP, Aarsland D. A magnetic resonance imaging study of patients with Parkinson's disease with mild cognitive impairment and dementia using voxel-based morphometry. J Neurol Neurosurg Psychiatry. 2007 Mar;78(3):254-9.

12. Janvin CC, Larsen JP, Salmon DP, Galasko D, Hugdahl K, Aarsland D. Cognitive profiles of individual patients with Parkinson's disease and dementia: comparison with dementia with lewy bodies and Alzheimer's disease. Mov Disord. 2006 Mar;21(3):337-42.

13. Aarsland D, Karlsen K. Neuropsychiatric aspects of Parkinson's disease. Current psychiatry reports. 1999 Oct;1(1):61-8. 